\title{
Analisis Pengaruh Kepuasan Kerja, Komitmen Organisasi, dan Keterlibatan Kerja Pada Kinerja Karyawan Bank Muamalat Surakarta
}

\author{
Agus Marimin ${ }^{1)}$, Harun Santoso ${ }^{2)}$ \\ Institut Teknologi Bisnis AAS Indonesia \\ *Email korespondensi: agusmarimin@ gmail.com
}

\begin{abstract}
The purpose of this study was to examine the positive effect of job satisfaction, organizational commitment, and job involvement on employee performance at Bank Muamalat Surakarta. This research methodology using explanatory research type, the researcher conducted a survey and jumped into the research location by giving questionnaires to the employees of Bank Muamalat Surakarta directly. This study uses a quantitative method, where this method is used to test the hypothesis. The population of this research is all employees of Bank Muamalat Surakarta as many as 60 people as well as the research sample. The sampling technique used total sampling technique, where the number of samples was the same as the population. The data analysis technique used multiple regression analysis, $\mathrm{t}$ test, $\mathrm{F}$ test, and $\mathrm{R} 2$ test. The results showed that there was a significant influence between job satisfaction factors $\left(\mathrm{X}_{1}\right)$ on the employee performance of Bank Muamalat Surakarta, there was a significant influence between organizational commitment factors $\left(\mathrm{X}_{2}\right)$ on the employee performance of Bank Muamalat Surakarta, there was a significant influence between job involvement factors $\left(\mathrm{X}_{3}\right)$ on the performance of employees of Bank Muamalat Surakarta.
\end{abstract}

Keywords: job satisfaction; organizational commitment; work involvement; employee performance

Saran sitasi: Marimin, A., \& Santoso, H. (2020). Analisis Pengaruh Kepuasan Kerja, Komitmen Organisasi, dan Keterlibatan Kerja Pada Kinerja Karyawan Bank Muamalat Surakarta. Jurnal Ilmiah Ekonomi Islam, 6(03), 703708. doi: http://dx.doi.org/10.29040/jiei.v6i3.1467

\section{DOI: http://dx.doi.org/10.29040/jiei.v6i3.1467}

\section{PENDAHULUAN}

Kinerja merupakan gambaran mengenai tingkat pencapaian pelaksaan suatu program kegiatan atau kebijakan dalam mewujudkan sasaran, tujuan, visi, dan misi organisasi yang dituangkan melalui perencanaan strategis suatu organisasi. Kinerja dapat diketahui dan diukur jika individu atau sekelompok karyawan telah mempunyai kriteria atau standar keberhasilan tolak ukur yang telah ditetapkan oleh organisasi (Moeheriono, 2012). Kinerja menurut Mangkunegara (2013) adalah hasil kerja secara kualitas dan kuantitas yang dicapai oleh seseorang karyawan dalam melaksanakan tugasnya sesuai dengan tanggung jawab yang diberikan kepadanya. Kinerja merupakan suatu fungsi dari motivasi dan kemampuan. Kinerja karyawan merupakan hal yang sangat penting dalam upaya perusahaan untuk mencapai tujuannya. Kinerja yang lebih tinggi mengandung arti terjadinya peningkatan efisiensi, efektivitas, atau kualitas yang lebih tinggi dari penyelesaian serangkaian tugas yang dibebankan kepada seorang karyawan dalam organisasi.

Kinerja karyawan secara umum dipengaruhi oleh dua faktor, yaitu faktor internal dan eksternal (Ismail, 2010). Faktor internal meliputi kepuasan kerja dan komitmen organisasional. Sedangkan faktor eksternal meliputi kepemimpinan, keamanan dan keselamatan kerja, serta budaya organisasi. Kinerja karyawan dalam perusahaan dipengaruhi oleh budaya organisasi dan kepuasan karyawan. Salah satu faktor internal yang dapat mempengaruhi kinerja karyawan yang perlu diperhatikan adalah komitmen organisasional, dikarenakan komitmen organisasi merupakan dimensi perilaku penting yang dapat digunakan untuk menilai kecendrungan karyawan untuk bertahan sebagai anggota organisasi. Komitmen merupakan identifikasi dan keterkaitan seseorang yang relatif kuat terhadap organisasi (Sapitri \& Suryalena, 2016). 


\section{Jurnal Ilmiah Ekonomi Islam, 6(03), 2020, 704}

Komitmen organisasi memegang peranan penting dalam meningkatkan kinerja karyawan (Sapitri, 2016). Komitmen organisasi sebagai salah satu sikap dalam pekerjaan diartikan sebagai orientasi seseorang terhadap organisasi dalam arti kesetiaan, identifikasi, dan keterlibatan (Muchlas, 2008). Keterlibatan tugas atau kerja itu berarti mengidentifikasikan organisasi/perusahaan yang memperkerjakan seseorang.

Keterlibatan kerja akan meningkat jika anggota organisasi tersebut menghadapi suatu situasi yang penting untuk didiskusikan bersama, misalnya kebutuhan dan kepentingan pribadi yang ingin dicapai oleh anggota. Apabila kebutuhan tersebut dapat terpenuhi maka akan membuat anggota tersebut lebih berkomitmen terhadap organisasi. Anggota itu akan menyadari pentingnya berusaha dan memberikan kontribusi bagi organisasi (Rahmawaty, 2015). Keterlibatan kerja merupakan bentuk partisipasi dalam diri individu untuk berusaha semaksimal mungkin guna mencapai komitmen yang tinggi terhadap organisasi. Hal ini semakin diperjelas dengan hasil-hasil penelitian sebelumnya, seperti penelitian Kartiningsih (2007), Rehman (2011) menunjukkan bahwa keterlibatan kerja memiliki pengaruh positif dan signifikan terhadap komitmen organisasi.

Kepuasan kerja adalah perbedaan antara jumlah imbalan yang diterima pekerja dengan jumlah yang mereka yakini seharusnya mereka terima atau derajad terhadap mana seseorang menganggap positif atau negatif tentang pekerjaanya. Antoni (2013) mengungkapkan bahwa kepuasan kerja berhubungan erat dengan sikap karyawan terhadap pekerjan sendiri, situasi kerja, kerjasama antara pimpinan dengan sesama karyawan, dan setiap individu mempunyai tingkat kepuasan yang berbeda-beda sesuai dengan sistem nilai yang ada pada dirinya.

Menurut Gibson, I. Donelly (2003) menjelaskan bahwa ada lima faktor yang mempengaruhi kepuasan kerja, yaitu:

a. Gaji; gaji dan upah yang diterima karyawan dianggap sebagai refleksi caran pandang manajer mengenai kontribusi karyawan terhadap organisasi. uang tidak hanya membantu orang untuk memenuhi kebutuhan dasar, tetapi memberikan kepuasan pada tingkat berikutnya.

b. Pekerjaan yang dilakukan; jenis pekerjaan yang dilakukan dapat merupakan sumber kepuasan. Pekerjaan yang dapat memberikan kepuasan adalah pekerjaan yang menarik dan menantang, dan tidak membosankan dan pekerjaan itu dapat memberikan status.

c. Promosi; kesempatan untuk berkembang di organisasi dapat menjadi sumber kepuasan.

d. Supervisor; kemampuan supervisor untuk memberikan bantuan teknis dan dukungan moral dapat meningkatkan kepuasan kerja. Misalnya memberikan karyawan kesempatan berpartisipasi dalam membuat keputusan.

e. Rekan kerja; rekan kerja dapat memberikan bantuan secara teknis dan dapat mendukung secara sosial akan meningkatkan kepuasan kerja karyawan.

Komitmen adalah dorongan atau keinginan dari dalam individu untuk menunjang keberhasilan organisasi sesuai tujuan dan lebih mengutamakan kepentingan organisasi (Antoni, 2013). Menurut Robbins, komitmen organisasi sebagai suatu keadaan dimana seorang karyawan memihak pada suatu organisasi itu (Sartika, 2014). Dengan adanya komitmen organisasi karyawan diharapkan menjadi loyal dan tidak terjadi turnover karyawan dan kinerja yang dihasilkan memuaskan perusahaan. Menurut Meldhom (2014) yang dicirikan oleh faktor psikologis yaitu keinginan yang kuat untuk tetap menjadi anggota organisasi, keinginan untuk berusaha sekuat tenaga demi organisasi, dan kepercayaan yang pasti dan penerimaan terhadap nilai-nilai dan tujuan-tujuan organisasi. Kuntjoro (2002) mendefinisikan komitmen organisasi adalah kondisi di mana individu tertarik terhadap tujuan, nilai-nilai, dan sasaran organisasinya. Selanjutnya Herscovitch dan Meyer menyatakan komitmen organisasi adalah sejauh mana seorang anggota mengidentifikasi tujuan dan nilainilai organisasi serta bersedia mengerahkan usaha untuk mencapai kesuksesan (Eslami \& Gharakhani, 2012).

Robbins menyebut bahwa keterlibatan kerja sebagai derajat sejauh mana orang mengidentifikasi diri dengan pekerjaan, aktif berpartisipasi di dalamnya, dan mempertimbangkan kinerja penting bagi kesejateraan pribadi. menurut pengertian ini, tenaga kerja yang memiliki job involvement tinggi mengidentifikasi diri terhadap pekerjaan dan sangat sangat bertanggung jawab atas pekerjaan yang dilakukan (Tobing, 2009). Keterlibatan kerja adalah derajat dimana individu dikenal dari pekerjaannya, berpartisipasi aktif didalamnya dan menganggap prestasi penting untuk harga diri. Cilliana \& Mansoer (2008) menyatakan keterlibatan kerja adalah seberapa 
besar identifikasi secara psikologis individu terhadap pekerjaannya. Makin besar individu tersebut mengidentifikasikan dirinya dengan pekerjaannya, maka keterlibatan kerja semakin tinggi. Namun, perlu diingat bahwa individu yang terlibat dalam pekerjaannya belum tentu merasa senang dengan pekerjaannya karena pada kenyataannya individu yang merasa tidak senang dengan pekerjaannya juga dapat memiliki derajat keterlibatan yang sama dengan individu yang menyukai pekerjaannya.

Kinerja merupakan gambaran mengenai tingkat pencapaian pelaksaan suatu program kegiatan atau kebijakan dalam mewujudkan sasaran, tujuan, visi, dan misi organisasi yang dituangkan melalui perencanaan strategis suatu organisasi. Kinerja dapat diketahui dan diukur jika individu atau sekelompok karyawan telah mempunyai kriteria atau standar keberhasilan tolak ukur yang telah ditetapkan oleh organisasi (Moeheriono, 2012).

Kinerja menurut Mangkunegara (2013) adalah hasil kerja secara kualitas dan kuantitas yang dicapai oleh seseorang karyawan dalam melaksanakan tugasnya sesuai dengan tanggung jawab yang diberikan kepadanya. Kinerja merupakan suatu fungsi dari motivasi dan kemampuan (Mangkunegara, 2013); (Tho'in, 2019). Kinerja karyawan merupakan hal yang sangat penting dalam upaya perusahaan untuk mencapai tujuannya. Kinerja yang lebih tinggi mengandung arti terjadinya peningkatan efisiensi, efektivitas, atau kualitas yang lebih tinggi dari penyelesaian serangkaian tugas yang dibebankan kepada seorang karyawan dalam organisasi. Menurut Schuler \& Jackson (2005) karyawan berkinerja bagus apabila fasilitator-fasilitator berikut ini adalah: kemampuan, minat menjalankan pekerjaan, peluang bertumbuh dan maju, tujuan teridentifikasi dengan jelas, kepastian tentang apa yang diharapkan, umpan balik seberapa baik mereka menjalankan tugas, imbalan bagi bekerja dengan baik, hukuman bagi yang berkinerja buruk, kekuasan mendapatkan sumber daya guna menjadikan pekerjaan. Kinerja karyawan perlu sekali adanya suatu penilaian untuk memberikan satu peluang atau harapan yang baik kepada para karyawan atas rencana karier mereka yang dilihat dari kekuatan serta kelemahan (Tanujaya, 2014).

a. Tujuan Penilaian Kerja

Mangkunegara (2013), tujuan penilaian kinerja yaitu:

1) Meningkatkan saling pengertian antara karyawan tentang persyaratan kinerja.
2) Mencatat dan mengakui hasil kerja seorang karyawan, sehingga mereka termotivasi untuk berbuat yang lebih baik, atau sekurang-kurangnya berprestasi sama dengan prestasi yang terdahulu.

3) Memberikan perluang kepada karyawan untuk mendiskusikan keinginan dan aspirasinya dan meningkatkan kepedulian terhadap karier atau pekerjaan yang diembannya sekarang.

4) Mendefinisikan atau merumuskan kembali sasaran masa depan, sehingga karyawan termotivasi untuk berprestasi sesuai dengan potensinya.

5) Memeriksa rencana pelaksanaan dan pengembangan yang sesuai dengan kebutuhan pelatihan, khusus rencana diklat, dan kemudian menyetujui rencana itu jika tidak ada hal-hak yang perlu diubah.

b. Pengukuran Kinerja

Menurut Sutrisno (2009), pengukuran kinerja diarahkan pada enam aspek:

1) Hasil kerja: tingkat kuantitas maupun kualitas yang telah dihasilkan dan sejauh mana pengawasan dilakukan.

2) Pengetahuan pekerjaan: tingkat pengetahuan yang terkait dengan tugas pekerjaan yang ajan berpengaruh langsung terhadap kuantitas dan kualitas dari hasil kerja,

3) Inisiatif: tingkat inisiatif selama menjalankan tugas pekerjaan khususnya dalam hal penanganan masalah-masalah yang timbul.

4) Kecakapan mental: tingkat kemampuan dan kecepatan dalam menerima insturksi kerja dan menyesuaikan dengan cara kerja serta situasi kerja yang ada.

5) Sikap: tingkat semangat kerja serta sikap positif dalam melaksanakan tugas pekerjaan.

6) Disiplin waktu dan absensi: tingkat ketepatan waktu dan tingkat kehadiran.

\section{METODOLOGI PENELITIAN}

Penelitian ini dengan menggunakan jenis penelitian explanatory, peneliti melakukan survey dan terjun ke tempat penelitian dengan memberikan kuesioner kepada para karyawan Bank Muamalat Surakarta secara langsung. Penelitian ini menggunakan metode kuantitatif, dimana metode ini digunakan untuk menguji hipotesis.Populasi penelitian ini adalah seluruh karyawan Bank Muamalat Surakarta sebanyak 60 orang sekaligus sebagai sampel penelitian. Teknik pengambilan 
Jurnal Ilmiah Ekonomi Islam, 6(03), 2020, 706

sampel menggunakan teknik total sampling technique, dimana jumlah sampel sama dengan populasi
(Sugiyono, 2008). Teknik analsis data menggunakan analisis regresi berganda, uji t, uji $\mathrm{F}$, dan uji $\mathrm{R}^{2}$.

\section{HASIL PENELITIAN}

3.1 Regresi Linear Berganda

Tabel 1.Hasil Analisis Data Regresi Linear Berganda

\begin{tabular}{|l|l|l|l|l|}
\hline \multicolumn{1}{|c|}{ Variabel } & \multicolumn{1}{|c|}{ Koefisien Regresi } & \multicolumn{1}{c|}{$\mathbf{t}_{\text {hitung }}$} & \multicolumn{1}{c|}{$\mathbf{t}_{\text {tabel }}$} & \multicolumn{1}{c|}{ Signifikan } \\
\hline Kepuasan kerja & 0,260 & 2,819 & 1,67 & 0,007 \\
\hline Komitmen Organisasi & 0,138 & 2,309 & 1,67 & 0,025 \\
\hline Keterlibatan Kerja & 0,237 & 2,482 & 1,67 & 0,016 \\
\cline { 1 - 2 } Constanta & $-2,796$ & & \\
\cline { 1 - 2 } Adj.R Square & 0,410 & & & \\
\cline { 1 - 2 } R square & 0,440 & &
\end{tabular}

Sumber: data primer yang diolah

Berdasarkan hasil uji pengolahan data tabel di atas, maka dapat diperoleh persamaan regresi linier berganda sebagai berikut:

$\mathrm{Y}=-2,796+0,260 \mathrm{X} 1+0,138 \mathrm{X} 2+0,237 \mathrm{X} 3$

Berdasarkan persamaan linier berganda di atas dapat diuraikan sebagai berikut:

a. Nilai konstanta $(-2,796)$

Konstanta bernilai negatif menunjukkan bahwa apabila tidak ada faktor kepuasan kerja (X1), komitmen organisasi (X2), dan keterlibatan kerja (X3) maka kinerja (Y) akan menurun. Dengan demikian dapat diketahui bahwa kinerja dipengaruhi oleh faktor kepuasan kerja, komitmen organisasi dan keterlibatan kerja sangat kuat.

b. Besarnya nilai koefisien regresi faktor kepuasan kerja senilai 0,260 . Hal ini menunjukkan bahwa adanya hubungan searah yang signifikan antara faktor kepuasan kerja (X1) terhadap kinerja (Y). Artinya apabila kepuasan kerja semakin tinggi maka kinerja akan mengalami peningkatan.

c. Besarnya nilai koefisien regresi faktor komitmen organisasi senilai 0,138. Hal ini menunjukan bahwa Koefisien ada pengaruh positif yang signifikan terhadap kinerja, artinya apabila komitmen organisasi semakin baik, maka kinerjanya akan semakin baik.

d. Besarnya nilai koefisien regresi faktor keterlibatan kerja seniali 0,237 . Hal ini menunjukan nilai positif, yaitu terdapat hubungan searah yang signifikan antara faktor keterlibatan kerja terhadap variabel kinerja, artinya jika keterlibatan kerja semakin baik maka kinerja akan meningkat.

\subsection{Analisis Uji t}

a. Pengujian pengaruh faktor kepuasan kerja terhadap kinerja.

Pada taraf signifikan 0,05 diperoleh $\mathrm{t}_{\text {hitung }}$ sebesar 2,819 $>t_{\text {tabel }}$ 1,67 maka Ho ditolak. Berarti dapat disimpulkan bahwa ada pengaruh yang signifikan antara faktor kepuasan kerja (X1) pada kinerja karyawan Bank Muamalat Surakarta.

b. Pengujian pengaruh faktor komitmen organisasi terhadap kinerja

Pada taraf signifikan 0,05 diperoleh $\mathrm{t}_{\text {hitung }}$ sebesar $2.309>t_{\text {tabel }}$ 1,67 maka Ho ditolak.Berarti dapat disimpulkan bahwa ada pengaruh yang signifikan antara faktor komitmen organisasi (X2) pada kinerja karyawan Bank Muamalat Surakarta.

c. Pengujian pengaruh faktor keterlibatan kerja terhadap kinerja.

Pada taraf signifikan 0,05 diperoleh $\mathrm{t}$ hitung sebesar $2.482>\mathrm{t}$ tabel 1,67 maka Ho ditolak. Berarti dapat disimpulkan bahwa ada pengaruh yang signifikan antara faktor keterlibatan kerja (X3) pada kinerja karyawan Bank Muamalat Surakarta.

3.3 Uji F dilakukan untuk melihat pengaruh variabel independen secara simultan terhadap variabel dependen. Hasil pengolahan data menggunakan SPSS dapat dilihat pada tabel berikut ini. 
Tabel 2 Uji F

ANOVA $^{\mathrm{a}}$

\begin{tabular}{|ll|r|r|r|r|r|}
\hline Model & Sum of Squares & df & Mean Square & F & \multicolumn{1}{c|}{ Sig. } \\
\hline \multirow{3}{*}{1} & Regression & 414,141 & 3 & 138,047 & 373,303 &, $000^{\mathrm{b}}$ \\
& Residual & 20,709 & 56 &, 370 & & \\
& Total & 434,850 & 59 & & & \\
\hline
\end{tabular}

a. Dependent Variable: kinerja

b. Predictors: (Constant), keterlibatan kerja, komitmen organisasi, kepuasan kerja Sumber: data primer yang diolah

Tabel di atas menunjukkan adanya nilai $\mathrm{F}_{\text {hitung }}=$ 373,303 dengan sig $=0,000<5 \%$, sehingga dapat diinterpretasikan bahwa nilai $\mathrm{F}$ yang dihitung tersebut signifikan yang berarti bahwa variabel kepuasan kerja, komitmen organisasi, dan keterlibatan kerja secara simultan berpengaruh signifikan terhadap variabel kinerja karyawan Bank Muamalat Surakarta.

\subsection{Koefisien determinasi $\left(\mathrm{R}^{2}\right)$}

Dalam melakukan pengukuran model regresi diperlukan pengujian koefisien determinasi $\left(R^{2}\right)$. Koefisien determinasi $\left(\mathrm{R}^{2}\right)$ digunakan untuk mengukur tingkat kecocokan atau kesempurnaan model regresi. Tabel dibawah ini menunjukkan hasil dari pengujian koefisien determinasi.

Tabel 3. Hasil Uji Koefisien Determinasi $\left(\mathbf{R}^{2}\right)$

Model Summary ${ }^{b}$

\begin{tabular}{|l|r|r|r|r|r|}
\hline Model & \multicolumn{1}{|c|}{$\mathrm{R}$} & $\mathrm{R}$ Square & Adjusted R Square & Std. Error of the Estimate & Durbin-Watson \\
\hline 1 &, $976^{\mathrm{a}}$ &, 952 &, 950 &, 608 &, 639 \\
\hline
\end{tabular}

a. Predictors: (Constant), keterlibatan kerja, komitmen organisasi, kepuasan kerja

b. Dependent Variable: kinerja

Sumber: data primer yang diolah

Hasil pengujian koefisien determinasi $\left(\mathrm{R}^{2}\right)$ menunjukkan pengaruh variabel independen kepuasan kerja, komitmen organisasi, dan keterlibatan kerja. Berdasarkan pengujian koefisien determinasi diperoleh nilai $\left(\mathrm{R}^{2}\right)$ sebesar 0,950. Dengan demikian variabel independen kepuasan kerja, komitmen organisasi, dan keterlibatan kerja mempengaruhi kinerja sebesar 95,0\%. Sedangkan 5,0\% kinerja dipengaruhi oleh faktor yang lain.

\section{KESIMPULAN}

Berdasarkan pembahasan di atas, maka dapat disimpulkan bahwa berdasarkan hasil pengujian hipotesis pada taraf signifikan 0,05 diperoleh $\mathrm{t}$ hitung sebesar 2,819 > t tabel 1,67 maka dapat disimpulkan bahwa ada pengaruh yang signifikan antara faktor kepuasan kerja (X1) pada kinerja karyawan Bank Muamalat Surakarta. Berdasarkan hasil pengujian hipotesis pertama diketahui Pada taraf signifikan 0,05 diperoleh $\mathrm{t}$ hitung sebesar $2.309>\mathrm{t}$ tabel 1,67 maka dapat disimpulkan bahwa ada pengaruh yang signifikan antara faktor komitmen organisasi (X2) pada kinerja karyawan Bank Muamalat Surakarta. Berdasarkan hasil pengujian Pada taraf signifikan
0,05 diperoleh $\mathrm{t}$ hitung sebesar $2.482>\mathrm{t}$ tabel 1,67 maka dapat disimpulkan bahwa ada pengaruh yang signifikan antara faktor keterlibatan kerja (X3) pada kinerja karyawan Bank Muamalat Surakarta.

\section{UCAPAN TERIMA KASIH}

Peneliti ucapkan banyak terima kasih kepada Kementerian Pendidikan dan Kebudayaan yang telah memberikan dukungan sepenuhnya terutama dukungan pendanaan dalam pelaksanaan penelitian ini.

\section{DAFTAR PUSTAKA}

Antoni, Z. (2013). Pengaruh Budaya Organisasi, Gaya Kepemimpinan, Komitmen Organisasi Dan Locus Of Control Terhadap Kepuasan Kerja Auditor Di Pekanbaru (Doctoral dissertation, Universitas Islam Negeri Sultan Syarif Kasim Riau).

Dan Mansoer, C. Wilman. D. 2008. Pengaruh Kepuasan Kerja, Keterlibatan Kerja, Stres Kerja dan Komitmen Organisasi Terhadap Kesiapan Untuk Berubah Pada Karyawan PT Bank Y. Jurnal Psikologi, 14(2), 151-164. 


\section{Jurnal Ilmiah Ekonomi Islam, 6(03), 2020, 708}

Eslami, J., \& Gharakhani, D. (2012). Organizational commitment and job satisfaction. ARPN Journal of Science and Technology, 2(2), 85-91.

Gibson, I. Donelly (2003). Las organizaciones, comportamiento, estructura y proceso. Editorial McGraw Hill. México.

Ismail, M. I. (2010). Kinerja dan kompetensi guru dalam pembelajaran. Lentera Pendidikan: Jurnal Ilmu Tarbiyah dan Keguruan, 13(1), 44-63.

Kartiningsih, K. (2007). Analisis Pengaruh Budaya Organisasi dan Keterlibatan Kerja Terhadap Komitmen Organisasi Dalam Meningkatkan Kinerja Karyawan (Studi Pada PT. Bank Tabungan Negara (Persero) Cabang Semarang)(Doctoral dissertation, program Pascasarjana Universitas Diponegoro).

Kuntjoro, Z. S. (2002). Komitmen organisasi. Jakarta: www. e-psikologi. com.

Mangkunegara, A. P. (2013). Manajemen Sumber Daya Manusia: Cetakan Kesebelas. PT Remaja Rosdakarya, Bandung.

Meldhom, A. (2014). Pengaruh Kepemimpinan dan Komitmen Terhadap Kedisiplinan Kerja Pegawai Pada Kantor Camat Sungai Apit (Doctoral dissertation, Universitas Islam Negeri Sultan Syarif Kasim Riau).

Moeheriono, E., \& Si, D. M. (2012). Pengukuran Kinerja Berbasis Kompetensi.

Muchlas, M. (2008). Perilaku organisasi. Yogyakarta: Gajahmada Pers.

Rahmawaty, E. (2015). Hubungan Keterlibatan Kerja dan Kepuasan Kerja Dengan Kinerja Pegawai Administratif Universitas Islam Negeri Sultan Syarif Kasim Riau (Doctoral dissertation, Universitas Islam Negeri Sultan Syarif Kasim Riau).

Rehman, R. R. (2011). Effect of organizational change on employee job involvement: Mediating role of communication, emotions and psychological contract. Information Management and Business Review, 3(3), 178-184.
Sapitri, R., \& Suryalena, S. (2016). Pengaruh komitmen organisasi terhadap kinerja karyawan perusahaan listrik negara area pekanbaru. Jurnal Online Mahasiswa Fakultas Ilmu Sosial dan Ilmu Politik Universitas Riau, 3(2), 1-9.

Sartika, D. (2014). Pengaruh kepuasan kerja dan gaya kepemimpinan transformasional terhadap keinginan keluar karyawan dengan komitmen organisasi sebagai variabel mediasi (studi kasus di cv. Putra tama jaya). Management Analysis Journal, 3(2).

Schuler, R. S., \& Jackson, S. E. (2005). A quartercentury review of human resource management in the US: The growth in importance of the international perspective. Management revue, 11-35.

Sugiyono. (2008). Metode penelitian pendidikan:(pendekatan kuantitatif, kualitatif dan $R \& D)$. Alfabeta.

Sutrisno, E. (2009). Manajemen Sumber Daya Manusia Edisi pertama. Jakarta: Kencana Prenada Media Group.

Tho'in, M. (2019). Profitability of Islamic Commercial Banks in Indonesia. MEC-J (Management and Economics Journal),3(3), 277-288.Standar UMP di PT. Sinergi Integra Services, Jakarta). Jurnal Psikologi Esa Unggul, 12(02).

Tnujaya, W. (2014). Hubungan Kepuasan Kerja dengan Kesejahteraan Psikologis (Psychological Well Being) pada Karyawan Cleaner (Studi Pada Karyawan Cleaner Yang Menerima Gaji Tidak Sesuai

Tobing, D. S. K. (2009). Pengaruh komitmen organisasional dan kepuasan kerja terhadap kinerja karyawan PT. Perkebunan Nusantara III di Sumatera Utara. Jurnal manajemen dan kewirausahaan, 11(1), 31-37. 